\title{
De tijd van ontstaan van het oudste Goudse stadsrecht en van Gouda als stedelijke nederzetting
}

\section{J. G. KRUISHEER}

Op 19 juli 1272 vaardigde graaf Floris V van Holland en Zeeland ten gunste van de Zeeuwse edelman heer Nikolaas van Kats en de burgers van Gouda een belangrijke oorkonde uit. De tekst ervan is opgenomen in het deel van het Oorkondenboek dat zojuist is verschenen ${ }^{56}$. Het is inderdaad een belangrijke oorkonde. Het is de oudste overgeleverde tekst waarin sprake is van de burgers van Gouda, en daarmee van Gouda als stad, als stedelijke nederzetting. Ik geef heel vluchtig de inhoud van het stuk weer. De graaf kent heer Nikolaas het stadsgebied toe, kennelijk als leen, en omschrijft de omvang van dat gebied; - hij geeft de burgers die er wonen vrijstelling van tolbetaling in het gehele graafschap; - hij zegt de burgers die van een geweldmisdrijf worden verdacht, zekere bescherming toe tegen aanhouding en beslaglegging op hun eigendommen (tenminste, als de verdachten voldoende gegoed zijn); — bepaald wordt verder dat de Gouwenaren hetzelfde recht zullen genieten als de burgers van Leiden bezitten en dat hun rechtscollege, in geval van onzekerheid, bij het Leidse college raad kan inwinnen; - en, tot slot, dat hun militaire verplichtingen bestaan uit het leveren van vijf man, die zij op eigen kosten moeten uitrusten en onderhouden.

Wie tot nu toe deze tekst, de oudste Goudse stadsrechtoorkonde, wilde gebruiken als bron voor de vroege geschiedenis van de stad, kwam voor aanzienlijke problemen te staan. Een half dozijn auteurs van de achttiende eeuw tot heden heeft, ieder op zijn beurt, iets over de oorkonde te berde gebracht. In de meeste gevallen komt het er op neer dat de tekst, of een bepaald gedeelte ervan, 'verdacht' zou zijn, of 'bevreemdend ', of 'anachronistisch', of regelrecht onecht, vervalst. Van den Bergh beschouwde de titel 'graaf van Zeeland' die Floris V naast de titel 'graaf van Holland' voert, als een anachronisme $^{57}$; Hugenholtz sloot zich bij die mening aan ${ }^{58}$. Ook het feit dat heer Nikolaas van Kats in deze oorkonde als begunstigde voorkomt, bevreemdde Van den Bergh; heer Nikolaas was immers geen heer van Gouda, maar ten hoogste voogd van de onmondige vrouwe van die $\operatorname{stad}^{59}$. Niermeyer beschouwde de toekenning van tolvrijdom als een onecht bestanddeel. De Gouwenaren zouden volgens hem pas tien jaar later, in 1282 , hun eerste tolprivilege hebben ontvangen ${ }^{60}$. Een volgend twistpunt betreft het feit dat de tekst in twee versies is overgeleverd, een Latijnse en een Nederlandse, twee versies die elkaar inhoudelijk niet geheel dekken en die beide alleen

56 Kruisheer, OHZ, III, 685-690, no. 1603.

57 Van den Bergh, OHZ, II, 104, no. 237, noot 1.

58 Rapport van F. W. N. Hugenholtz aan de burgemeester van Gouda, door G. S[chrijvers] weergegeven in de Goudsche Courant van 21 april 1959, 3.

59 Van den Bergh, OHZ, II, 104, no. 237, noot 1.

60 Bronnen voor de economische geschiedenis van het Beneden-Maasgebied, Eerste deel: 1104-1399, J.

F. Niermeyer, ed. ('s-Gravenhage, 1968) 34, no. 77. 
in de vorm van latere afschriften bekend zijn ${ }^{61}$. Van Mieris vermoedde dat de Nederlandse versie de oorspronkelijke is en de Latijnse een later vervaardigde, bekorte vertaling daarvan ${ }^{62}$. Hugenholtz huldigt die mening ook ${ }^{63}$. Daarentegen stelt de jongste auteur, Buiskool, mede op grond van een door mij aan hem gedane mondelinge mededeling, dat de Nederlandse versie pas in de veertiende eeuw de gedaante heeft gekregen waarin wij haar kennen, en dat de Latijnse tekst de oorspronkelijke oorkonde van 1272 weergeeft ${ }^{64}$. Weer een andere auteur, de vroegere Goudse archivaris Geselschap, vond de omschrijving van het stadsgebied 'ongebruikelijk' voor een stadsrechtoorkonde uit de dertiende eeuw ${ }^{65}$, en Buiskool oordeelt haar zelfs anachronistisch, dus onecht, want die omschrijving zou het stadsgebied weergeven in een omvang die dat gebied eerst later, in de veertiende eeuw, bereikt zou hebben ${ }^{66}$.

Het is allemaal niet gering: anachronistische titulatuur; bedenkelijk optreden van heer Nikolaas van Kats; onecht tolprivilege; omschrijving van het stadsgebied die niet klopt; omwerking van de tekst in de veertiende eeuw. Wat te denken van al die bezwaren tegen de echtheid? Wat kun je, als argeloze geschiedschrijver, met zo'n tekst aanvangen? Welke gegevens eruit kan men voor de geschiedenis van de dertiende eeuw eigenlijk nog gebruiken?

Hier ligt duidelijk een taak voor de tekstuitgever. Het gaat natuurlijk niet aan, het publiek deze tekst zonder meer aan te bieden en het van het bestaan van al die bedenkingen onkundig te laten. En het gaat ook niet aan, die bedenkingen zonder meer bij de teksteditie weer te geven en de gebruiker zelf maar te laten uitzoeken wat hij van al die opinies moet denken. De tekstuitgever heeft de plicht die bedenkingen stuk voor stuk op hun geldigheid te onderzoeken, van ieder ervan de waarde te bepalen en ze, voor zover ze onderling tegenstrijdig zijn, tegen elkaar af te wegen. De tekstuitgever moet, kortom, zelf ook onderzoeker zijn. Hij moet zich bij de genoemde onderzoekers voegen. Hij moet zich alle vragen stellen die de eerdere onderzoekers zich stelden, en alle verdere relevante gegevens die hem bekend zijn naar voren halen. En dat alles moet hij doen op een duidelijke en doorzichtige manier, en tegelijk met zo veel terughoudendheid dat de gebruiker van de editie zich niet bij voorbaat al een onmondige voelt.

61 Het origineel is niet overgeleverd. De Latijnse versie kennen wij uit een zeventiende-eeuwse druk, de Nederlandse uit enkele tientallen afschriften uit de veertiende tot de achttiende eeuw. Zie de opgave in het Oorkondenboek.

62 Groot charterboek der graaven van Holland, van Zeeland en heeren van Vriesland..., F. van Mieris, ed. (4 dln.; Leiden, 1753-1756) I, 363, noot.

63 Zie noot 58.

64 K. M. Buiskool, 'De ruimtelijke ontwikkeling van Gouda tot 1398' (onuitgegeven doctoraalscriptie middeleeuwse geschiedenis Universiteit van Amsterdam, 1988) 31-37; K.[M.] Buiskool, 'De Gouwestreek en Gouda. Een historisch-geografisch onderzoek', De schatkamer. Regionaal historisch tijdschrift, IV (1990) 13-14.

65 J. E. J. Geselschap, 'De opkomst van Gouda' in: A. Scheygrond, e. a., ed., Gouda zeven eeuwen stad. Hoofdstukken uit de geschiedenis van Gouda uitgegeven bij de herdenking van het 700-jarig bestaan van de stad Gouda in 1972 (Gouda, 1972) 26.

66 Buiskool, 'Ruimtelijke ontwikkeling Gouda', 25-27, 42-43; Buiskool, 'Gouwestreek en Gouda', 1314. 
Mijn poging om mij ten aanzien van de Goudse stadsrechtoorkonde van 1272 van deze taak te kwijten, begin ik bij de kwestie van de Zeeuwse titel die de graaf naast de Hollandse titel voert. Door onderzoek van alle grafelijke oorkonden tot het einde van de dertiende eeuw dat ik eerder ondernam, weten wij dat de graaf van Holland tot 1291 kortweg 'graaf van Holland' heet; - maar er zijn enkele uitzonderingen op die regel ${ }^{67}$. In een klein aantal oorkonden van vóór 1291 heet hij 'graaf van Holland en Zeeland'. Het betreft meestal oorkonden die in Vlaanderen of in Zeeland zijn opgesteld, en wel door de Vlaamse of de Zeeuwse belanghebbenden van die oorkonden. Nogal wat Vlamingen en Zeeuwen, zo mogen wij concluderen, beschouwden de graaf van Holland, die immers de grafelijke rechten in Zeeland uitoefende, als graaf van Zeeland en betitelden hem dienovereenkomstig. Ook de Goudse stadsrechtoorkonde heeft iets Zeeuws. De eerstgenoemde begunstigde van die oorkonde is immers niemand anders dan heer Nikolaas van Kats. Kennelijk hebben we hier met zo'n geval van doen waar een Zeeuwse scribent, hier wel iemand uit de omgeving van heer Nikolaas, de graaf van Holland mede als 'graaf van Zeeland' betitelt. Er is dus niets anachronistisch in het gebruik van die titel, zoals Van den Bergh meende ${ }^{68}$. En ook de mogelijkheid die Hugenholtz opperde, kunnen wij uitsluiten: namelijk dat de Zeeuwse titel in de veertiende eeuw zou zijn toegevoegd door een klerk die de tekst aldus aan de gebruiken van zijn tijd wilde aanpassen ${ }^{69}$. In dat geval zouden wij ook de titel 'heer van Friesland' hebben mogen verwachten. Vanaf 1291 heet de graaf namelijk 'graaf van Holland en Zeeland en heer van Friesland ${ }^{70}$. De aanwezigheid, naast de Hollandse titel, van alleen de Zeeuwse titel, dus zonder de Friese titel, versterkt juist het vermoeden van echtheid van de oorkonde, in plaats van tot een vermoeden van onechtheid te leiden.

$\mathrm{Nu}$ de bedenkingen van Van den Bergh tegen de aanwezigheid van heer Nikolaas van Kats. Heer Nikolaas was geen heer van Gouda, zegt Van den Bergh, maar vermoedelijk niet meer dan voogd over de Goudse erfdochter ${ }^{71}$. Uit andere bron weten wij dat heer Nikolaas inderdaad optrad als opvoeder van de minderjarige Sofie van der Gouwe (of van Gouda), en dat hij zijn pupil had uitgehuwelijkt aan een van zijn eigen toen nog minderjarige zonen $^{72}$. Zijn bevoegdheid als opvoeder ging dus heel ver, die bevoegdheid evenaarde als het ware de vaderlijke macht. Van den Berghs observatie dat heer Nikolaas hier als heer van Gouda lijkt op te treden is dus juist, maar dat hoeft, anders dan Van den Bergh vindt, geen argwaan te wekken.

Niermeyer stelt dat de bepaling in het stadsrecht die de Goudse burgers vrijstelt van tolbetaling, onecht is. De Gouwenaren kregen pas in 1282 tolvrijdom, en dat was toen

67 Kruisheer, Oorkonden en kanselarij, I, 103-104.

68 Van den Bergh, OHZ, 104, no. 237, noot 1.

69 Zie noot 58.

70 Kruisheer, Oorkonden en kanselarij, I, 103, 105-106.

71 Van den Bergh, OHZ, 104, no. 237, noot 1.

72 Bullarium Trajectense..., G. Brom, ed., I ('s-Gravenhage, 1891 ) 146-147, no. 359 ( 1285 juli 19). Paus Honorius IV gelast een onderzoek naar aanleiding van het verzoek van Jan van Renesse en Sofia om dispensatie van het huwelijksbeletsel dat erin bestond dat Nikolaas van Kats, die destijds als Sofia's opvoeder was opgetreden, haar ten huwelijk had toegezegd aan een van zijn eigen zonen, bloedverwanten van Jan. Dat genoemde Sofia identiek is met Sofia van der Gouwe blijkt uit de hierna in noot 74 te noemen oorkonde d. d. 1282 aug. 15. 
kennelijk voor de eerste maal, zegt Niermeyer, zodat de tolvrijstellingsbepaling in de stadsrechtoorkonde van 1272 niet echt kan zijn ${ }^{73}$. Er bestaat inderdaad een tolprivilege ten gunste van de burgers van Gouda uit het jaar $1282^{74}$, maar waarom dat stuk van 1282 kennelijk het eerste tolprivilege zou betreffen dat zij ooit ontvingen, zegt Niermeyer niet. Welke zijn overwegingen ook geweest mogen zijn, Niermeyer overtuigt ons niet. Zeker niet wanneer wij opmerken dat het tolprivilege van 1282 een verruiming betekent van de vrijdorh zoals wij die kennen uit het stadsrecht van 1272 . Volgens de tekst van 1272 gold de vrijdom alleen goederen die Goudse burgers toebehoorden en die op Goudse schepen werden vervoerd ${ }^{75}$. In 1282 werden alle goederen van Goudse burgers vrijgesteld, ook die welke op andere dan Goudse schepen lagen, mits die andere schepen toebehoorden aan personen die zelf vrijstelling genoten $^{76}$. Dus aanvankelijk, in 1272, beperkte tol vrijstelling; tien jaar later ruimere tol vrijstelling. Confrontatie met de oorkonde van 1282 levert dus geen argument tegen de echtheid van de stadsrechtoorkonde van 1272 op, maar, ook hier weer, eerder een argument ten gunste ervan.

De oorkonde van 1282 helpt ons meteen het probleem van de twee versies van het stadsrecht van 1272 op te lossen. De tekst van 1282, die in het Nederlands is gesteld, is namelijk geredigeerd met gebruikmaking van omvangrijke passages uit het stadsrecht van 1272, en wel uit de Nederlandse versie daarvan ${ }^{77}$. Toen men in 1282 het verruimde tolprivilege beoorkondde, kwam dus de Nederlandse versie van de stadsrechtoorkonde van 1272 ter tafel. Kennelijk vertegenwoordigt de Nederlandse versie van de stadsrechtoorkonde de oorspronkelijke tekst. De opvattingen van Van Mieris, Niermeyeren Hugenholtz die dat al vermoedden ${ }^{78}$, zijn dus juist. De mening die ik zelf eerder huldigde en die Buiskool overnam ${ }^{79}$, namelijk dat de Latijnse versie de oorspronkelijke is, is onjuist. De Latijnse versie, die trouwens alleen uit een zeventiende-eeuwse bron bekend is, moet inderdaad een bekorte vertaling of parafrase van de Nederlandse zijn.

En nu nog de kwestie van de omschrijving van het stadsgebied. Naar de mening van Geselschap zou alleen al het feit dat de omvang van het stadsgebied wordt omschreven, verdacht zijn ${ }^{80}$. Buiskool gaat nog verder. Zetten we de afmetingen van het stadsgebied die worden opgegeven op de kaart uit, dan blijkt de oostelijke grens van dat gebied te

73 Niermeyer, Bronnen Beneden-Maasgebied, 34, no. 77.

74 Van den Bergh, OHZ, II, 204, no. 462 (1282 aug. 15).

75 Kruisheer, $O H Z$, III, 689, no. 1603 ( 1272 juli 19), art. 2: '... dat alle die ghene de binnen deser vrieyt woenaftich sijn ende porters sijn, tollen vry varen seilen voer alle onse tollen doei' alle onse land mit horen eyghene scepen ende mit horen eyghene goede'.

76 Oorkonde d. d. 1282 aug. 15 in het later te verschijnen $O H Z$, IV (eerder in de editie: Van den Bergh, $O H Z$, II, 204, no. 462: '...dat alle die ghene die porters siin te Goude, binnen der vriheit van der poert woenachtich siin, moghen varen met haren eygheliken goede tol vri voer bi al onse tollen van al onsen lande, alsoe verre alse dat goet niet en leghet op scepes bodem dat tolbaer si'.

77 De ontleningen zullen in de editie van de oorkonde van 1282 aug. 15 in het vierde deel van het Oorkondenboek (in voorbereiding) door middel van petitdruk worden aangegeven.

78 Van Mieris, Groot charterboek, 1,363, noot; Niermeyer, Bronnen Beneden-Maasgebied, 34, no. 77; Rapport Hugenholtz weergegeven in de Goudsche Courant, 3.

79 Buiskool, 'Ruimtelijke ontwikkeling Gouda', 31-37; Buiskool, 'Gouwestreek en Gouda', 13-14.

80 Geselschap,'De opkomst van Gouda', 26. 
lopen langs de Omloopkade, door gebied dat in 1272 nog niet tot het graafschap Holland zou behoren; bovendien zou de watergang die langs die kade loopt eerst in het midden van de veertiende eeuw zijn gegraven. De desbetreffende omschrijving in het stadsrecht van 1272 zou dus onecht zijn ${ }^{81}$. Het is niet mogelijk Buiskools argumenten hier in alle details na te gaan. Dat is jammer, want het is interessante materie, en de auteur heeft er veel werk van gemaakt. Ik beperk mij hier tot de twee argumenten die mijns inziens de belangrijkste uit zijn betoog zijn. In de eerste plaats het argument dat de grens tussen Holland en het Sticht Utrecht in de dertiende eeuw nog langs de Gouwe liep, en niet een stuk ten oosten daarvan. Dat zal wel zo zijn, maar dat neemt niet weg dat de graaf van Holland de grens tussen zijn eigen graafschap en het gebied van de bisschop bij talrijke gelegenheden en op uiteenlopende manieren overschreed, bijvoorbeeld door het aangaan van verbintenissen met Stichtse heren, plaatselijke gemeenten en stedelijke ambachten ${ }^{82}$, en door ingrijpen in waterstaatsaangelegenhe$\operatorname{den}^{83}$. Juist in deze periode is het expansionistische optreden van de graaf van Holland in het Stichtse grensgebied duidelijk zichtbaar. Zijn optreden in Gouda in 1272 is er een voorbeeld van. Het tweede argument van Buiskool betreft de datering van de watergang langs de Omloopkade, de oostelijke grens vanhetGoudse stadsgebied zoals wij dat uit de omschrijving van 1272 kennen. Die watergang zou eerst in het midden van de veertiende eeuw zijn aangelegd, in het kader van het verleggen van een gedeelte van de Bloemendaalse Wetering. DatBuiskool de oorkonden van 1331 en van 1350 waarin het te wijzigen tracé van die wetering wordt beschreven, onjuist interpreteerr ${ }^{84}$,

81 Buiskool, 'Ruimtelijke ontwikkeling Gouda', 25-27, 42-43; Buiskool, 'Gouwestreek en Gouda', $13-$ 14.

82 Niermeyer, 'Het sticht Utrecht en het graafschap Holland', 289-293.

83 P. A. Henderikx, 'De zorg voor de dijken in het baljuwschap Zuid-Holland en in de grensgebieden ten oosten daarvan tot het einde van de 13e eeuw', Geografisch Tijdschrift, nieuwe reeks, XI (1977) 407-427, i.h.b. $414,417 \mathrm{vlg}$.

84 In 1331 vergunt heer Jan van Beaumont de belanghebbenden de Bloemendaalse Wetering te laten lopen 'door $t$ land van Bloemendale, van den Broeke ende van der vrijheyt oostwaerdt voorbij der poorte van der Goude door onse landt dat was sheeren van Steyne out in die IJsele' (GA Gouda, archief polder Bloemendaal no. 141, f. 1 ; druk naar een ander afschrift bij S. J. Fockema Andreae, 'Een zeshonderdjarige (De polder Bloemendaal bij Gouda, 1331 -4 October-1931 )', Tijdschrift van het Koninklijk Nederlandsch Aardrijkskundig Genootschap, tweede serie, XLVIII (1931) 1001-1002). Het tracé liep 'oostwaerdt', dat is in noordoostelijke richting, door het gebied van de stadsvrijheid om pas vervolgens, na het gerecht Willens te zijn binnengedrongen, naar de IJsel, dus naar het zuiden af te buigen. (Zie over de interpretatie van de windrichtingen J. W. Muller, 'Eene cartographische vraag nopens de orienteering in vroegeren tijd', Tijdschrift van het Koninklijk Nederlandsch Aardrijkskundig Genootschap, tweede serie, XL ( 1923) 120126. Jan van Beaumont had Willens kort tevoren door koop van de heer van Stein verkregen. S. J. Fockema Andreae, 'Stein. Het ontstaan van een vrije hooge heerlijkheid op de grenzen van Holland en van hare bestuursorganen', Tijdschrift voor Geschiedenis, XLVII (1932) 401.) In 1350 bleek het noodzakelijk dat de wetering gedeeltelijk werd verlegd, aangezien zij liep door terrein waar men toen een stadsuitbreiding wilde realiseren. Ook nu werd het nieuwe tracé beschreven als in noordoostelijke richting ('oostwaard off) door het Goudse stadsgebied lopende (GA Gouda, archief polder Bloemendaal no. 141, f. 2v). Een en ander wraakt Buiskools identificatie van de verlegde gedeelten van de wetering met de Kolfwetering resp. de wetering langs de Omloopkade. Die twee weteringen lopen immers noord-zuid. Het was niet, zoals Buiskool stelt, het middelste gedeelte van de Bloemendaalse Wetering dat gehandhaafd werd en het laatste gedeelte dat werd verlegd, maar juist andersom: de benedenloop bleef ongewijzigd en het middelste stuk (tussen Broekpolder en Willens, door het gebied van de stadsvrijheid heen) werd omgelegd. Buiskool, 'Ruimtelijke ontwikkeling Gouda', 25-27; Buiskool, 'Gouwestreek en Gouda', 8. 
is hier niet van belang omdat die wetering zelf hier niet van belang is. De oostelijke grens van het stadsgebied wordt namelijk niet door die wetering gevormd, maar door de kade evenwijdig waaraan de wetering loopt. Die kade is ongetwijfeld ouder dan de wetering. Het is de zijdwinde die de ontginning Oude Gouwe, waarbinnen de nederzetting Gouda ontstond, beschermde tegen 'van boven', uit de richting van Willens komend water. Die zijdwinde is per definitie even oud als de ontginning Oude Gouwe, dat wil zeggen iets jonger dan de elfde-eeuwse ontginning Willens. Niets pleit er dan ook voor, de omschrijving van het Goudse stadsgebied in de stadsrechtoorkonde van 1272 als een veertiende-eeuwse interpolatie te beschouwen.

Alle bezwaren die in de loop der tijd tegen de oudste Goudse stadsrechtoorkonde zijn ingebracht, hebben we onderzocht, en we hebben ze naar mijn mening alle kunnen weerleggen. De tekst zoals die ons is overgeleverd, en wel de Nederlandse versie ervan, is, zo moeten wij concluderen, de tekst van de oorkonde zoals die in 1272 werkelijk werd uitgevaardigd. We kunnen die tekst zonder reserves ten aanzien van zijn echtheid, benutten als bron voor de vroege geschiedenis van Gouda.

Maar er is meer. Op grond van een ruim aantal detailonderzoekingen zijn wij langzamerhand in staat een zekere typologie van de dertiende-eeuwse stadsrechtoorkonde in Holland en Zeeland te geven ${ }^{85}$. De Goudse stadsrechtoorkonde voldoet in voldoende mate aan die typologie om de resultaten van die eerdere onderzoekingen te kunnen gebruiken voor vergelijkend onderzoek. De Goudse stadsrechtoorkonde is, evenals 'de' Hollands-Zeeuwse, kennelijk een zogeheten destinatarisprodukt, een oorkonde vervaardigd niet door de grafelijke kanselarij maar door de zorgen van de belanghebbenden. Het gebruik van de Zeeuwse graventitel interpreteerden wij zojuist al als de inbreng van heer Nikolaas van Kats en diens Zeeuwse omgeving. Het is duidelijk dat ook de Gouwenaren zelf een aandeel hadden in de formulering van de tekst. Die tekst vertoont - en dat is een tweede punt van overeenkomst - een duidelijke gelaagdheid. Klaarblijkelijk is hij niet in één keer, maar in fasen verspreid over zekere tijd opgesteld. De aanhef van de oorkonde, waar heer Nikolaas als begunstigde figureert, vormt één laag. Een andere laag wordt gevormd door de rest van de tekst, waarin heer Nikolaas niet meer voorkomt en waar alleen de burgers van Gouda als begunstigden worden genoemd. Het heeft er alle schijn van dat de eerstgenoemde laag, die met Nikolaas van Kats, jonger is dan de andere. Met andere woorden, die andere laag lijkt een in 1272 al bestaande optekening te vertegenwoordigen. Die in 1272 al bestaande optekening was een oorkonde, want ze vertoont een bekrachtigingsformule; - bekrachtigingsformule waarin alleen van de burgers en niet van heer Nikolaas van Kats wordt gerept! De oudste laag van de stadsrechtoorkonde van 1272 is dus afkomstig uit een stadsrechtoorkonde die de burgers van Gouda al bij

85 Kruisheer, 'Het ontstaan van de oudste Zeeuwse stadsrechtoorkonden', 275-304; Kruisheer, Het ontslaan van de stadsrechtoorkonden van Haarlem, Delft en Alkmaar; J.[G.] Kruisheer, 'Stadsrechtbeoorkonding en stedelijke ontwikkeling', in: E. H. P. Cordfunke, e. a., ed., De Hollandse stad in de dertiende eeuw (Zutphen, 1988) 44-54; Kruisheer, 'Het ontstaan van de oudste Leidse stadsrechtoorkonden', 182203. Onderzoekingen naar het ontstaan van de stadsrechtoorkonden van Geertruidenberg, 's-Gravenzande, Vlaardingen, Medemblik en Beverwijk zijn in voorbereiding. 
een eerdere gelegenheid hadden verworven. Op grond van deze constatering mogen wij veronderstellen - en dit is een derde punt van gelijkenis - dat Gouda in 1272 al een nederzetting met een zeker stedelijk karakter was; dat de stadsrechtoorkonde van 1272 geen stichtingsoorkonde is, maar de vastlegging behelst, de sanctionering van een situatie die in de voorafgaande periode was gegroeid; - en klaarblijkelijk is het in 1272 niet eens de eerste keer dat die gegroeide situatie aldus werd gesanctioneerd. Dat moet op zijn laatst rond het midden van de dertiende eeuw al het geval zijn geweest. Maar, bij alle punten van overeenkomst met de 'typisch' Hollands-Zeeuwse stad van de dertiende eeuw, is er, als ik het goed zie, ook een belangrijk punt van verschil. Alle door mij tot nu toe onderzochte stadsrechtoorkonden betreffen steden op het oude land; op gronden direkt achter de duinen (Domburg, Westkapelle, Haarlem, Alkmaar), op de oudere kleigronden (Middelburg, Leiden, Zierikzee), of in het al eerder ontgonnen laagveen (Delft). Gouda betreft een stedelijke nederzetting in de onmiddellijke nabijheid van gebieden waar in de dertiende eeuw de ontginningen nog in volle gang waren. De grootscheepse ontginning van het laagveen en de vorming van stedelijke nederzettingen hebben op zijn minst één factor gemeen. Beide ontwikkelingen werden gestuwd dooreen sterke bevolkingsgroei. Dezelfde demografische druk die de aanzet gaf tot het op grote schaal in ontginning nemen van de veenwildernis, was een stuwende kracht bij het tot ontwikkeling komen van stedelijke nederzettingen. We moeten natuurlijk niet te gauw naar pakkende conclusies willen grijpen, maar het heeft er veel van weg dat de samenhang tussen ontginning en stadsvorming in het geval van Gouda even heel duidelijk wordt, met behulp van moderne oorkondeneditie. 


\section{De loopbaan van de klerk Melis Stoke 86}

\section{J.W.J. BURGERS}

Een van de belangrijkste bronnen voor onze kennis van de geschiedenis van het graafschap Holland en Zeeland aan het eind van de dertiende en het begin van de veertiende eeuw wordt gevormd door de Rijmkroniek van Holland. Dit werk is, naar wordt aangenomen, geschreven door de grafelijke klerk Melis Stoke. Zijn kroniek is vooral van belang omdat daarin door een goed-geïnformeerde auteur uitvoerig, en in een levendige stijl, verslag wordt gedaan van de dramatische politieke gebeurtenissen in de jaren 1295-1305. Dank zij dit relaas zijn we bijvoorbeeld op de hoogte van de toedracht van de moorden op graaf Floris V en Wolfert van Borsele, en kennen we het verloop van de Vlaamse oorlog, die Holland op de rand van de afgrond bracht. Daarbij komt dat de Rijmkroniek een waar monument is van de Nederlandse taal. De kroniek is een van de oudste volledig overgeleverde literaire teksten in de volkstaal, voor de Noordelijke Nederlanden zelfs de alleroudste, en het eerste voorbeeld van het genre van de rijmkroniek. Ook voor taal- en literatuurhistorici is dit werk dus van groot belang. Al met al zijn er genoeg redenen om te proberen de vele problemen op te lossen, die nog met het ontstaan en het auteurschap van de kroniek samenhangen ${ }^{87}$.

De recentste editie van de Rijmkroniek dateert uit 1885. De uitgever ervan, W. G. Brill, gaf toen als bijlage een facsimile van een oorkonde van graaf Willem III van Holland, uitgevaardigd op 29 november 1305, en bestemd voor de stad Zierikzee ${ }^{88}$. Dit stuk is links onderaan, door dezelfde hand als die de tekst schreef, ondertekend met de naam $a$. stoke. Volgens Brill hebben we hier voor ons een oorkonde die eigenhandig is geschreven door Amelis (oftewel Melis) Stoke, de auteur van de Rijmkroniek. Sindsdien heeft niemand deze conclusie van Brill in twijfel getrokken, maar evenmin is er ooit iets met die vondst gedaan.

Enige tijd geleden stuitte ik op Brills facsimile, in het kader van een uitgebreid onderzoek naar het schrift in de documentaire bronnen in Holland en Zeeland in de dertiende eeuw. Ik herkende het handschrift van de oorkonde meteen: dit was een notarius uit de Hollandse grafelijke kanselarij die al door J. G. Kruisheer in diens proefschrift was geïdentificeerd, waar hij kanselarijhand U heet ${ }^{89}$. Ook M. Gysseling had in zijn monumentale editie van het Corpus van Middelnederlandse teksten deze

\footnotetext{
86 De in deze lezing in voorlopige vorm bekend gemaakte ontdekking over Melis Stoke is, samen met de daaruit voortvloeiende nieuwe bestudering van de Rijmkroniek, onderwerp van een thans lopend onderzoek door de auteur.

87 Voor een overzicht van literatuur, edities en de discussie met betrekking tot de Rijmkroniek zie M. Carasso-Kok, Repertorium van verhalende historische bronnen uit de middeleeuwen ('s-Gravenhage, 1981) 388-390, no. 358, alsmede de hierna genoemde literatuur ter zake.

88 Rijmkroniek van Melis Stoke, W. G. Brill, ed. (2 din.; Utrecht, 1885; ongew. herdr. in één band; Utrecht, 1983). Het facsimile staat in deel 2 vooraan op de ongenummerde pagina's, in de herdruk achter in het boek. De betreffende oorkonde berust in het gemeentearchief van Zierikzee, nr. 21.
}

89 Kruisheer, Oorkonden en kanselarij, I, 42-43. 